\title{
Liquid-Liquid Extraction of Tetravalent Zirconium from Acidic Chloride Solutions Using Cyanex 272
}

\author{
B. Ramachandra REDDY, ${ }^{* \dagger}$ J. Rajesh KUMAR, ${ }^{* * *}$ and A. Varada REDDY** \\ *Inorganic Chemistry Division, Indian Institute of Chemical Technology (CSIR), Hyderabad-500007, India \\ **Analytical Chemistry Division, Department of Chemistry, SriVenkateswara University, Tirupati-517502, India
}

\begin{abstract}
The liquid-liquid extraction of zirconium(IV) from acidic chloride solutions was carried out with Cyanex 272 as an extractant diluted in kerosene. An increase of the acid concentration decreased the percentage extraction of metal, which

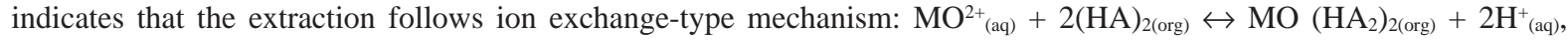
where, $\mathrm{M}=\mathrm{Zr}(\mathrm{IV})$; $\mathrm{HA}=$ Cyanex 272. The extraction of $\mathrm{Zr}(\mathrm{IV})$ increases with an increase of the extractant concentration. In a plot of $\log D v s . \log$ [extractant], $\mathrm{M}$ is linear with a slope of $\sim 2$, indicating the association of two moles of extractant with the extracted metal species. On the other hand, the extraction decreases with an increase of the $\mathrm{H}^{+}$ion concentration. A plot of $\log D v s . \log \left[\mathrm{H}^{+}\right]$gave a straight line with a negative slope of 1.7 , indicating the exchange of two moles of hydrogen ions for every mole of $\mathrm{Zr}(\mathrm{IV})$. The effect of the $\mathrm{Cl}^{-}$ion concentration at a constant concentration of $\left[\mathrm{H}^{+}\right]$did not show any change in the $D$ values. The addition of sodium salts enhanced the percentage extraction of metal, and followed the order of $\mathrm{NaSCN}>\mathrm{NaNO}_{3}>\mathrm{Na}_{2} \mathrm{SO}_{4}>\mathrm{NaCl}$. The stripping of metal from the loaded organic (L.O) with different acids indicated sulfuric acid to be the best stripping agent. An increase of the temperature during the extraction and stripping stages increases the metal transfer, showing that the process is exothermic. The synergism, regeneration and recycling capacity of Cyanex 272; the extraction behavior of associated elements, such as $\mathrm{Hf}(\mathrm{IV}), \mathrm{Ti}(\mathrm{IV}), \mathrm{Al}(\mathrm{III}), \mathrm{Fe}(\mathrm{III})$; and IR spectra of the extracted Zr-Cyanex 272 complex were studied.
\end{abstract}

(Received July 18, 2003; Accepted September 29, 2003)

Zirconium is used in the nuclear industry as a shielding material and as a catalyst in organic reactions in the manufacture of water-repellent textiles; it is also used in dye pigments and ceramics. A survey of the literature showed that a limited number of extractants have been used for the extraction of zirconium. Organophosphorus compounds, namely $\mathrm{TBP}^{1-5}$ and D2EHPA, ${ }^{6-11}$ have been extensively employed in solventextraction studies of zirconium. Amines, such as Aliquat 336 and Alamine 336, ${ }^{12}$ have been used for the extraction of zirconium. Also, other extractants studied have been dihexyl $\mathrm{N}, \mathrm{N}$-diethylmethylcarbamoyl phosphonate, ${ }^{13}$ isopropylphosphonicacid mono(1-hexyl-4-ethyl)octylester (PT-2, HL) ${ }^{14}$ and octyl(phynyl) $N, N$-diisobutylcarbamoyl methylphosphineoxide (CMPO). ${ }^{15}$

Cyanex 272 is a bis(2,4,4-trimethylpentyl) phosphinic acid. It is a well-known solvent-extraction reagent showing favorable extraction and stripping properties for a range of metals. It has high selectivity for the separation of cobalt(II) and nickel(II), ${ }^{16-18}$ and shows an ability to reject calcium(II). ${ }^{19}$ The above extractant has the advantage of being a liquid, and is completely miscible with all commonly used hydrocarbons. Despite the large number of studies reporting the solvent extraction of metals with Cyanex 272, it has not been reported for the solvent extraction of zirconium.

The present study reports on the solvent extraction behavior of zirconium(IV) from low acidic chloride solutions with Cyanex 272 in kerosene. Various experimental variables, such as the effect of acid, the effect of $\mathrm{Cl}^{-} / \mathrm{H}^{+}$at constant $\mathrm{H}^{+} / \mathrm{Cl}^{-}$

\footnotetext{
† To whom correspondence should be addressed.

E-mail: brcreddy_iict@yahoo.com
}

concentration, the extractant and the metal concentration, the nature of diluents, the effect of salts, the temperature, the loading capacity, the stripping of metal from a loaded organic, the regeneration and recycling capacity of an extractant, the extraction of associated elements and the infrared spectral data of a metal complex have been studied.

\section{Experimental}

\section{Apparatus}

The concentrations of $\mathrm{Zr}(\mathrm{IV})$ and $\mathrm{Hf}(\mathrm{IV})$ in the aqueous phase were determined by the Xylenol Orange (XO) method ${ }^{20}$ at 535 $\mathrm{nm}$ and $\mathrm{Ti}(\mathrm{IV})$ by the hydrogen peroxide method $^{20}$ at $410 \mathrm{~nm}$ using a GBC CINTRA 10e UV-VIS-DRS spectrometer. Analyses of $\mathrm{Fe}(\mathrm{III})$ and $\mathrm{Al}(\mathrm{III})$ were carried out using a Perkin Elmer Model A 300 AAS. The IR spectrum of the solid complex was recorded using a FTIR-Nicolet (USA)-740spectrophotometer. A Julabo shaker (Temp SW 22 Model) was used for a temperature effect.

\section{Reagents}

Cyanex 272 and Cyanex 923, supplied by Cytec, Canada, were used without purification. Tributyl phosphate (TBP), supplied by SRL, Bombay, India was used. Di- $n$-octyl sulfoxide (DOSO) was prepared according to a reported procedure. ${ }^{21}$ As a source of $\mathrm{Zr}(\mathrm{IV}), \mathrm{ZrOCl}_{2} \cdot 8 \mathrm{H}_{2} \mathrm{O}$ (Fluka, $98 \%$ ) was used. Working solutions of $\mathrm{Zr}(\mathrm{IV})$ were prepared fresh and used for extraction experiments. Distilled kerosene (160 $200^{\circ} \mathrm{C}$ ) was used as a diluent. It was colorless and mostly aliphatic in nature. All other reagents used were of analytical 
reagent grade.

\section{Solvent-extraction procedure}

Equal volumes $(10 \mathrm{ml})$ of the aqueous phase containing, the desired concentrations of $\mathrm{Zr}(\mathrm{IV})$ or other metals, and the organic phase containing the extractant, Cyanex 272, were equilibrated for $30 \mathrm{~min}$ in glass stopped bottles using a mechanical shaker. Preliminary experiments on the kinetics of metal extraction showed that equilibrium was achieved within $20 \mathrm{~min}$ of contact. After phase disengagement, the aqueous phase was separated and its metal concentrations were estimated by the XO method. The concentration of the metal in the organic phase was calculated from the mass balance. All of the experiments were conducted at room temperature $\left(30 \pm 1{ }^{\circ} \mathrm{C}\right)$, except for those involving a temperature effect. The distribution ratio $(D)$ was calculated as the concentration of metal present in the organic phase to that part in the aqueous phase at equilibrium. When required, the metal concentration in the organic phase was determined by stripping a suitable aliquot with dilute $\mathrm{HCl}$, followed by an analysis by the $\mathrm{XO}$ method.

\section{Preparation of solid complex}

A Zr-Cyanex 272 solid complex was prepared by loading 0.005 M Cyanex 272 in chloroform by repeated contact of fresh portions of metal solutions $(0.001 \mathrm{M})$ for $30 \mathrm{~min}$. Finally, the loaded organic (L.O) phase was separated and filtered through a Whatman phase separator (1PS). The diluent from the L.O was removed by a rotavac pump, which resulted in the formation of a semi-solid metal complex. A drop of the $\mathrm{Zr}$ (IV) complex was kept on a $\mathrm{KBr}$ pellet and placed under an IR lamp to completely evaporate chloroform. The IR spectra of the extracted metal complex and pure Cyanex 272 were recorded for a comparison.

\section{Results and Discussion}

Extraction mechanism and species

The extraction equilibrium of zirconium(IV) from hydrochloric acid solutions with Cyanex 272 as an extractant may be represented as

$$
\mathrm{ZrO}^{2+}{ }_{(\mathrm{aq})}+2(\mathrm{HA})_{2(\mathrm{org})} \stackrel{K_{\mathrm{ex}}}{\longrightarrow} \mathrm{ZrO}\left(\mathrm{HA}_{2}\right)_{2(\mathrm{org})}+2 \mathrm{H}^{+}{ }_{(\mathrm{aq})},
$$

where $K_{\mathrm{ex}}$ denotes the equilibrium constant and $(\mathrm{HA})_{2}$ refers to the dimeric form of the extractant (Cyanex 272). It has been reported elsewhere that these extractants will exist as dimers under the present experimental conditions: ${ }^{18,22,23}$

$$
\begin{aligned}
K_{\mathrm{ex}} & =\frac{\left[\mathrm{ZrO}\left(\mathrm{HA}_{2}\right)_{2}\right]\left[\mathrm{H}^{+}\right]^{2}}{\left[\mathrm{ZrO}^{2+}\right]\left[(\mathrm{HA})_{2}\right]^{2}}, \\
K_{\mathrm{ex}} & =\frac{D\left[\mathrm{H}^{+}\right]^{2}}{\left[(\mathrm{HA})_{2}\right]^{2}},
\end{aligned}
$$

$$
\text { Where } D=\frac{\left[\mathrm{ZrO}\left(\mathrm{HA}_{2}\right)_{2}\right]}{\left[\mathrm{ZrO}^{2+}\right]} \text {. }
$$

Taking the logarithm of Eq. (3) and rearranging,

$$
\log D=\log K_{\text {ex }}+2 \log \left[(\mathrm{HA})_{2}\right]-2 \log \left[\mathrm{H}^{+}\right] .
$$

Analyzing the experimental data of the distribution ratio $(D)$ as a function of the $\mathrm{H}^{+}$ion and the extractant concentration at a constant value of other parameters allows an estimation of the number of extractant molecules associated with the extracted

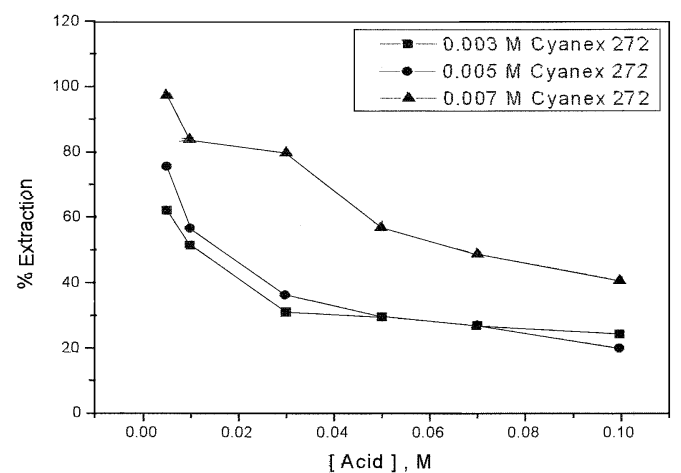

Fig. 1 Effect of the hydrochloric acid concentration on the exrtraction of $\mathrm{Zr}(\mathrm{IV})$. $\mathrm{Zr}(\mathrm{IV}), 0.001 \mathrm{M}$; Cyanex 272, $0.005 \mathrm{M}$.

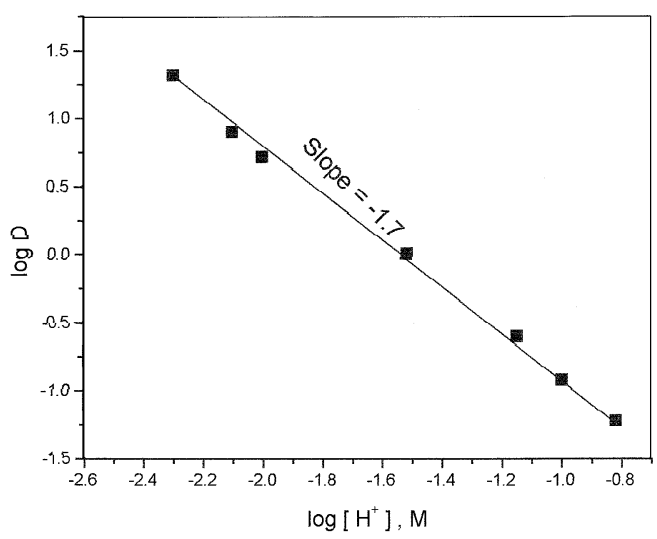

Fig. 2 Effect of the hydrogen ion concentration on the distribution ratio of $\mathrm{Zr}(\mathrm{IV})$ at constant $\mathrm{Cl}^{-}$ion. $\mathrm{Zr}(\mathrm{IV}), 0.001 \mathrm{M}$; $\left[\mathrm{Cl}^{-}\right], 0.3 \mathrm{M}$; Cyanex 272, $0.005 \mathrm{M}$.

metal complex.

The extraction of zirconium(IV) with Cyanex $272(0.003$ 0.005 and $0.007 \mathrm{M}$ ) as a function of the hydrochloric acid concentration showed (Fig. 1) an inverse dependence with the acidity, indicating the release of $\mathrm{H}^{+}$ions from the extractant during the extraction process. On the other hand, the effect of the chloride ion concentration in the range of $0.01-0.3 \mathrm{M}$ at a constant $\mathrm{H}^{+}$ion concentration $(0.01 \mathrm{M})$ was studied for mixtures of $\mathrm{HCl}$ and $\mathrm{NaCl}$ using a $0.005 \mathrm{M}$ extractant, indicating that the percent extraction of the metal remains constant with an increase of the chloride ion concentration $(D=1.2 \pm 0.05)$. The effect of the hydrogen-ion concentration on the distribution ratio of $\mathrm{Zr}(\mathrm{IV})$ was studied in the range of $\mathrm{H}^{+}$ions from 0.005 to 0.15 $\mathrm{M}$ at a constant $\mathrm{Cl}^{-}$ion concentration $(0.3 \mathrm{M})$ in the aqueous phase. $\log D$ vs. $\log \left[\mathrm{H}^{+}\right]$plot (Fig. 2) gave a straight line with a negative slope of about 1.7, indicating the exchange of two moles of $\mathrm{H}^{+}$for every mole of metal ion during the extraction process.

The effect of the Cyanex 272 concentration ( 0.001 to 0.015 $\mathrm{M})$ on the extraction of $\mathrm{Zr}(\mathrm{IV})(0.001 \mathrm{M})$ from $0.01 \mathrm{M}$ hydrochloric acid solutions was investigated, and the results are depicted in Fig. 3. It is clear from this figure that the extraction of zirconium increases with an increase of the extractant concentrations. A plot of $\log D$ versus $\log \left[(\mathrm{HA})_{2}\right]$ gave a straight line with a slope 2.2, indicating that two moles of the extractant (HA $\equiv$ Cyanex 272) were involved in the extracted complexes of $\mathrm{Zr}(\mathrm{IV})$. The calculated value of $K_{\mathrm{ex}}$ was found to 


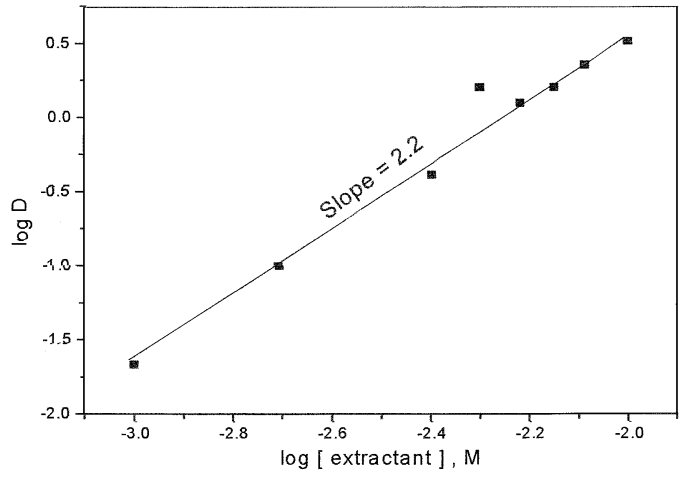

Fig. 3 Plot of $\log D$ vs. $\log [$ extractant], M. $\mathrm{Zr}(\mathrm{IV}), 0.001 \mathrm{M} ; \mathrm{HCl}$, $0.01 \mathrm{M}$.

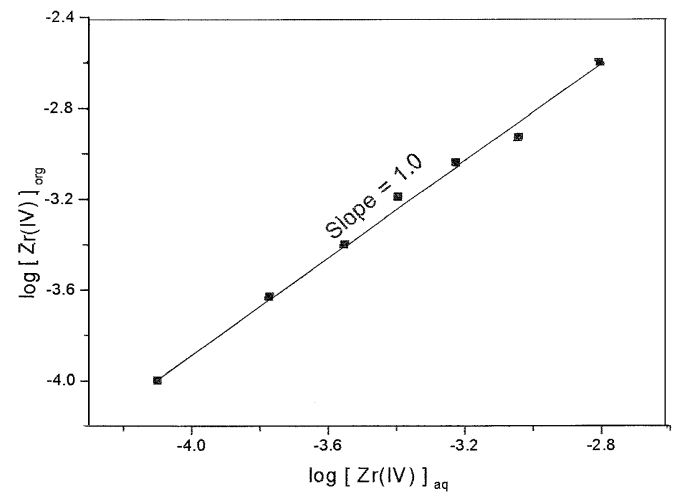

Fig. 4 Effect of the metal concentration on the extraction of $\mathrm{Zr}$ (IV). $\mathrm{HCl}, 0.01 \mathrm{M}$; Cyanex 272, 0.005 M.

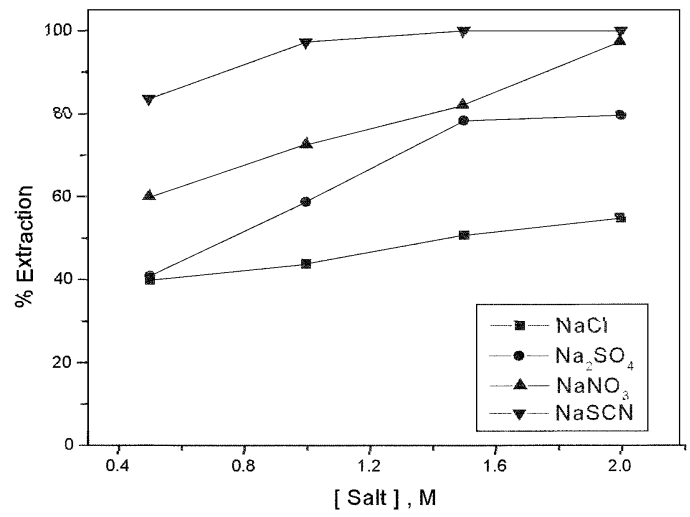

Fig. 5 Effect of sodium salts on the extraction of $\mathrm{Zr}(\mathrm{IV}) . \mathrm{Zr}$ (IV), $0.001 \mathrm{M} ; \mathrm{HCl}, 0.01 \mathrm{M}$; Cyanex 272, $0.005 \mathrm{M}$.

be 3.4 .

The effect of the zirconium concentration on the extraction process was investigated using Cyanex 272 (0.005 M) from hydrochloric acid solutions $(0.01 \mathrm{M})$. The extraction of zirconium(IV) was found to be independent of the metal-ion concentration in the aqueous phase. A log-log plot (Fig. 4) of the equilibrium organic-phase metal concentration against the aqueous-phase metal concentration is linear with a slope of $\sim 1.0$, indicating the extraction of the mononuclear species into the organic phase. The species extracted into the organic phase appeared to be $\mathrm{ZrO}\left(\mathrm{HA}_{2}\right)_{2}$.
Table 1 Effect of temperature on zirconium extraction and stripping

\begin{tabular}{ccc}
\hline Temperature $/{ }^{\circ} \mathrm{C}$ & Extraction, $\%$ & Stripping, $\%$ \\
\hline 30 & 36.3 & 30.1 \\
40 & 50.1 & 47.4 \\
50 & 64.0 & 64.5 \\
60 & 73.7 & 77.3 \\
\hline
\end{tabular}

Extraction: 0.001 M Zr(IV), 0.01 M HCl, 0.005 M Cyanex 272. Stripping: $\mathrm{Zr}(\mathrm{IV})$ in L.O, $246 \mathrm{mg} \mathrm{l}^{-1}$; $4 \mathrm{M} \mathrm{HCl}$.

\section{Effect of salts}

The effect of salts, such as $\mathrm{NaCl}, \mathrm{Na}_{2} \mathrm{SO}_{4}, \mathrm{NaNO}_{3}$ or $\mathrm{NaSCN}$, was studied in the concentration range of $0.5-2.0 \mathrm{M}$ on the extraction behavior of $0.001 \mathrm{M} \mathrm{Zr(IV)} \mathrm{from} 0.01 \mathrm{M} \mathrm{HCl}$ with $0.005 \mathrm{M}$ Cyanex 272. In the case of $\mathrm{NaCl}$, the percentage of extraction steadily increased with increasing the $\mathrm{NaCl}$ concentration. The percentage extraction was $39.8 \%$ in $0.5 \mathrm{M}$, and reached $54.8 \%$ in $2 \mathrm{M} \mathrm{NaCl}$ concentration. In the case of $\mathrm{Na}_{2} \mathrm{SO}_{4}$, the percentage of extraction was $40.8 \%$ in $0.5 \mathrm{M}$, salt, and reached $79.6 \%$ in $2 \mathrm{M}$ salt concentration. In the case of $\mathrm{NaNO}_{3}$, the percentage of extraction started at $60 \%$ in $0.5 \mathrm{M}$ salt concentrations and reached $97.3 \%$ in $2 \mathrm{M}$ salt concentrations. In the case of $\mathrm{NaSCN}$, the percentage of extraction started at $83.6 \%$ in $0.5 \mathrm{M}$ salt concentrations and reaches $100 \%$ in $1.0 \mathrm{M}$ salt concentrations, favoring better extraction of $\mathrm{Zr}(\mathrm{IV})$ than the other salts (Fig. 5). The enhancement in percent extraction in the presence of added salts may perhaps be due to a common ion effect as well as the presence of mixed metal salt species, that makes the metal more favorable for extraction. At a given concentration of the metal, extractant and acid, the percentage extraction followed in increasing order as $\mathrm{NaSCN}>\mathrm{NaNO}_{3}>$ $\mathrm{Na}_{2} \mathrm{SO}_{4}>\mathrm{NaCl}$.

\section{Effect of diluents and temperature}

The extraction of $\mathrm{Zr}(\mathrm{IV})$ from hydrochloric acid solutions $(0.01 \mathrm{M})$ using Cyanex $272(0.005 \mathrm{M})$ in various diluents was investigated. The results clearly demonstrate that the extraction of $\mathrm{Zr}(\mathrm{IV})$ varies with the nature of the diluent, and decreases in the following order: toluene $(D=0.11)<$ chloroform $(D=$ $0.18)<$ carbon tetrachloride, xylene $(D=0.30$ and 0.33$)<$ benzene, nitrobenzene $(D=0.40$ and 0.43$)<n$-hexane $(D=$ $0.52)<$ kerosene, cyclohexane $(D=0.57$ and 0.58$)<$ benzonitril $(D=0.66)$. The variation of the temperature in the range of 303 $-333 \mathrm{~K}\left( \pm 1^{\circ}\right)$ on the extraction of metal from an aqueous solution containing $0.001 \mathrm{M} \mathrm{Zr(IV)}$ and $0.01 \mathrm{M} \mathrm{HCl}$ using 0.005 M Cyanex 272 was studied. An increase in the temperature increased the extraction and the stripping of $\mathrm{Zr}(\mathrm{IV})$ from L.O (Table 1). The calculated values of $\Delta^{\circ} H$ from Arrhenius plots were -10.5 and $-13.7 \mathrm{kcal} \mathrm{mol}^{-1}$ for the extraction and stripping processes, indicating an exothermic reaction.

\section{Loading capacity of the extractant}

An aliquot of $10 \mathrm{ml}$ of $0.01 \mathrm{M}$ Cyanex 272 was repeatedly contacted at $303 \pm 1 \mathrm{~K}$ for $30 \mathrm{~min}$ with the same volume of aqueous solutions containing $0.001 \mathrm{M}$ of $\mathrm{Zr}(\mathrm{IV})$ and $0.01 \mathrm{M}$ $\mathrm{HCl}$. After equilibration, the phases were analyzed for the zirconium content. The amount of zirconium transferred into the organic phase in each contact was calculated based on the difference and the cumulative concentration of zirconium in the organic phase after each stage of contact was determined. A plot of cumulative $[\mathrm{Zr}(\mathrm{IV})]_{\text {org }}$ of Cyanex 272 versus the contact 


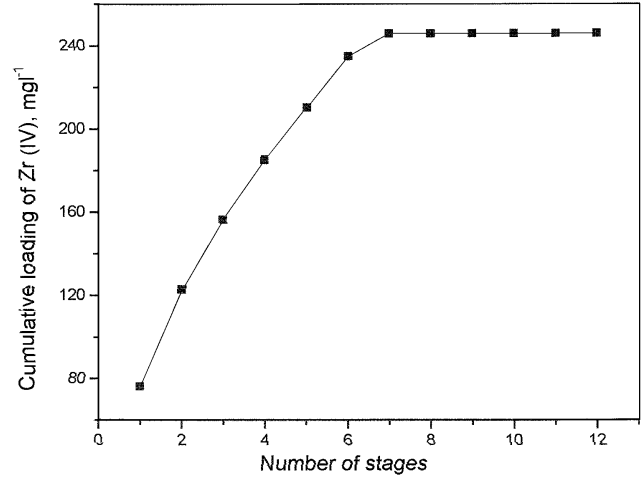

Fig. 6 Loading capacity of the extractant. $\mathrm{Zr}(\mathrm{IV}), 0.001 \mathrm{M} ; \mathrm{HCl}$, $0.01 \mathrm{M}$; Cyanex 272, $0.01 \mathrm{M}$.

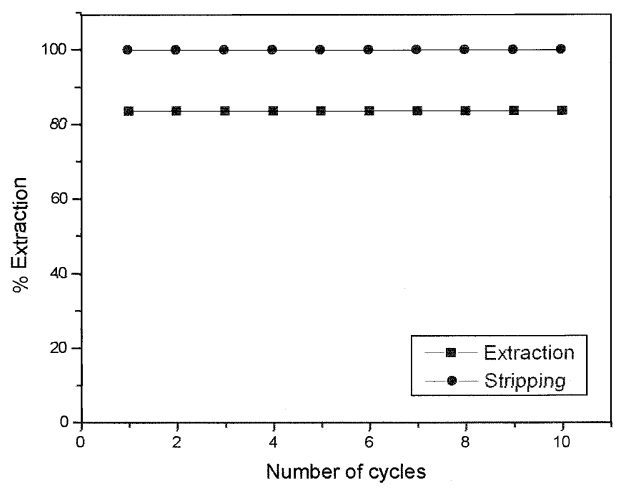

Fig. 7 Regeneration and recycling capacity of the extractant Extraction conditions: $\mathrm{Zr}(\mathrm{IV}), 0.001 \mathrm{M}$; $\mathrm{HCl}, 0.01 \mathrm{M}$; Cyanex 272, $0.007 \mathrm{M}$. Stripping conditions: $\mathrm{H}_{2} \mathrm{SO}_{4}, 0.5 \mathrm{M}$.

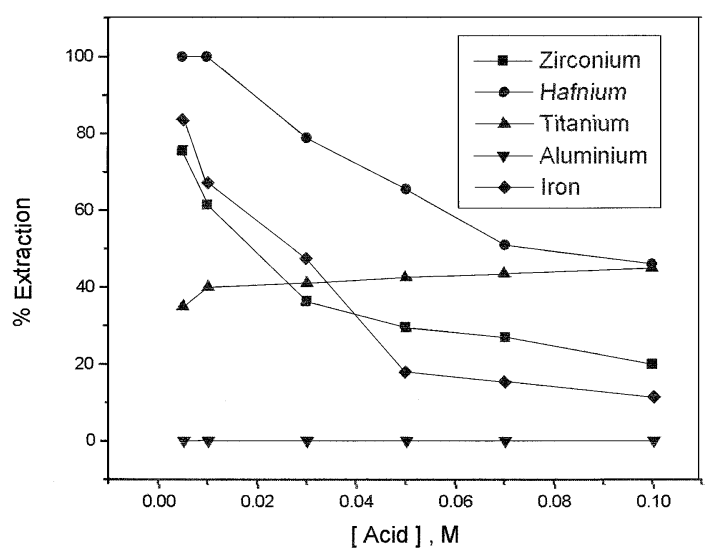

Fig. 8 Extraction of associated metals as a function of acid concentration. Metal, 0.001 M; Cyanex 272, 0.005 M.

number is given in Fig. 6. It is clear that the zirconium existing in the aqueous phase was extracted into the organic phase up to the 7th contact. An analysis of L.O showed that it contained $246 \mathrm{mg} \mathrm{l}^{-1} \mathrm{Zr}(\mathrm{IV})$.

\section{Stripping studies}

In any commercial extraction process it becomes imperative to back extract the metal from the loaded organic phase.
Table 2 Stripping of $\mathrm{Zr}(\mathrm{IV})$ from a loaded organic (246 $\mathrm{mg} \mathrm{l}^{-1}$ Zr) phase

\begin{tabular}{cclc}
\hline $\begin{array}{c}\text { Stripping } \\
\text { reagent }\end{array}$ & $\begin{array}{c}\text { Zr stripping, } \\
\%\end{array}$ & \multicolumn{1}{c}{ Stripping reagent } & $\begin{array}{c}\text { Zr stripping, } \\
\%\end{array}$ \\
\hline $1.0 \mathrm{M} \mathrm{HCl}$ & 12.3 & $3.0 \mathrm{M} \mathrm{HNO}_{3}$ & 6.40 \\
$2.0 \mathrm{M} \mathrm{HCl}$ & 16.0 & $4.0 \mathrm{M} \mathrm{HNO}$ & 7.80 \\
$3.0 \mathrm{M} \mathrm{HCl}$ & 23.6 & $1.0 \mathrm{M} \mathrm{HCl}+1 \% \mathrm{H}_{2} \mathrm{O}_{2}$ & 14.5 \\
$4.0 \mathrm{M} \mathrm{HCl}$ & 30.5 & $3.0 \mathrm{M} \mathrm{HCl}+1 \% \mathrm{H}_{2} \mathrm{O}_{2}$ & 28.8 \\
$0.1 \mathrm{M} \mathrm{H}_{2} \mathrm{SO}_{4}$ & 30.0 & $1.0 \mathrm{M} \mathrm{HCl}+5 \% \mathrm{H}_{2} \mathrm{O}_{2}$ & 16.0 \\
$0.5 \mathrm{M} \mathrm{H}_{2} \mathrm{SO}_{4}$ & 61.3 & $3.0 \mathrm{M} \mathrm{HCl}+5 \% \mathrm{H}_{2} \mathrm{O}_{2}$ & 30.0 \\
$1.0 \mathrm{M} \mathrm{H}_{2} \mathrm{SO}_{4}$ & 84.6 & $1.0 \mathrm{M} \mathrm{HNO}+1 \% \mathrm{H}_{2} \mathrm{O}_{2}$ & 5.50 \\
$2.0 \mathrm{M} \mathrm{H}_{2} \mathrm{SO}_{4}$ & 85.1 & $3.0 \mathrm{M} \mathrm{HNO}_{3}+1 \% \mathrm{H}_{2} \mathrm{O}_{2}$ & 7.80 \\
$3.0 \mathrm{M} \mathrm{H}_{2} \mathrm{SO}_{4}$ & 88.0 & $1.0 \mathrm{M} \mathrm{HNO}_{3}+5 \% \mathrm{H}_{2} \mathrm{O}_{2}$ & 10.2 \\
$4.0 \mathrm{M} \mathrm{H}_{2} \mathrm{SO}_{4}$ & 90.0 & $3.0 \mathrm{M} \mathrm{HNO}_{3}+5 \% \mathrm{H}_{2} \mathrm{O}_{2}$ & 12.3 \\
$1.0 \mathrm{M} \mathrm{HNO}_{3}$ & 3.60 & $1.0 \mathrm{M} \mathrm{H}_{2} \mathrm{SO}_{4}+1 \% \mathrm{H}_{2} \mathrm{O}_{2}$ & 100 \\
$2.0 \mathrm{M} \mathrm{HNO}_{3}$ & 5.10 & $3.0 \mathrm{M} \mathrm{H}_{2} \mathrm{SO}_{4}+1 \% \mathrm{H}_{2} \mathrm{O}_{2}$ & 100 \\
\hline
\end{tabular}

Zirconium stripping from a loaded organic solvent system, Cyanex 272 (0.005 M) containing $246 \mathrm{mg}$ zirconium(IV) was investigated using various stripping agents, such as $\mathrm{HCl}, \mathrm{H}_{2} \mathrm{SO}_{4}$ and $\mathrm{HNO}_{3}$, in the range of $0.1-4 \mathrm{M}$. The results are given in Table 2. In the case of $\mathrm{HCl}$ as a stripping agent, the percentage stripping increased with an increase in the acid concentration, and reached $12-30 \%$ of acid up to $4.0 \mathrm{M}$. With the addition of $1-5 \% \mathrm{H}_{2} \mathrm{O}_{2}$, the percentage stripping was unaffected. In the case of $\mathrm{H}_{2} \mathrm{SO}_{4}$, the percentage stripping increased with an increase in the acid concentration, and reached $~ 90 \%$ at $4.0 \mathrm{M}$ acid. From these results, it is clear that $\mathrm{H}_{2} \mathrm{SO}_{4}$ is the best and $\mathrm{HNO}_{3}$ is the poorest stripping agent.

\section{Recycling capacity of Cyanex 272}

Studies on the recycling capacity of 0.007 M Cyanex 272 for the extraction of $\mathrm{Zr}(\mathrm{IV})$ were carried out by first loading the extractant with an aqueous phase containing $0.001 \mathrm{M} \mathrm{Zr}(\mathrm{IV})$ and $0.01 \mathrm{M} \mathrm{HCl}$. Single-stage extraction gave L.O containing $76.3 \mathrm{mg} \mathrm{l}^{-1}$ zirconium, corresponding to a $99.8 \%$ theoretical efficiency. This L.O was stripping with $0.1 \mathrm{M} \mathrm{H}_{2} \mathrm{SO}_{4}$. The regenerated organic phase was then used for extraction. The results revealed a practically insignificant change in the extraction and stripping efficiency of extractant up to ten cycles of extraction (Fig. 7).

Comparison of the extraction behavior of $\operatorname{Zr}(I V)$ with other associated metal ions

The extraction behaviors of hafnium(IV), aluminium(III), titanium(IV) and iron(III) (0.001 $\mathrm{M}$ each) were investigated as a function of the hydrochloric acid concentration using $0.005 \mathrm{M}$ Cyanex 272 in kerosene as an extractant. The results are presented in Fig. 8. It is clear from these results that the percentage of extraction of $\mathrm{Hf}(\mathrm{IV}), \mathrm{Zr}(\mathrm{IV})$ and $\mathrm{Fe}(\mathrm{III})$ decreased with increasing acid concentration. On the other hand, the extraction of $\mathrm{Ti}(\mathrm{IV})$ increased with increasing acid concentration. The percentage extraction of $\mathrm{Al}(\mathrm{III})$ was nil.

\section{Synergism}

Blake et al. ${ }^{25}$ used the term "synergism" to describe the discovery of a definite enhancement in the extraction of uranium by using mixture of acidic alkyl phosphate and certain neutral organophosporous esters. The resulting mixture giving a better extraction of uranium than either the acid or the neutral phosphate alone. This effect is understood to be the replacement of one extractant in the extracted complex by the other, and also due to various other factors. This property of the 
Table 3 Distribution coefficient values of $\mathrm{Zr}(\mathrm{IV})$ using extractant and synergist mixtures

\begin{tabular}{ccccccc}
\hline S.No. & $\begin{array}{c}D_{\mathrm{A}}, \text { Extractant, } \\
0.005 \mathrm{M}\end{array}$ & $\begin{array}{c}\text { Concentration } \\
\text { of } \\
\text { synergist/M }\end{array}$ & $D_{\mathrm{B}}$ & $D_{\mathrm{A}+\mathrm{B}}$ & $\Delta D$ & S.C \\
\hline 1 & $1.06(\mathrm{C} 1)$ & $0.001(\mathrm{C} 2)$ & 0.25 & 2.10 & 0.79 & 0.205 \\
2 & $1.06(\mathrm{C} 1)$ & $0.005(\mathrm{C} 2)$ & 0.27 & 2.22 & 0.89 & 0.223 \\
3 & $1.06(\mathrm{C} 1)$ & $0.007(\mathrm{C} 2)$ & 0.46 & 3.35 & 1.83 & 0.343 \\
4 & $1.06(\mathrm{C} 1)$ & $0.001(\mathrm{D})$ & 0.06 & 1.72 & 0.59 & 0.185 \\
5 & $1.06(\mathrm{C} 1)$ & $0.005(\mathrm{D})$ & 0.12 & 1.80 & 0.62 & 0.183 \\
6 & $1.06(\mathrm{C} 1)$ & $0.007(\mathrm{D})$ & 0.18 & 2.22 & 0.98 & 0.253 \\
7 & $1.06(\mathrm{C} 1)$ & $0.001(\mathrm{~T})$ & 0.01 & 2.10 & 1.03 & 0.292 \\
8 & $1.06(\mathrm{C} 1)$ & $0.005(\mathrm{~T})$ & 0.07 & 2.22 & 1.09 & 0.291 \\
9 & $1.06(\mathrm{C} 1)$ & $0.007(\mathrm{~T})$ & 0.16 & 4.40 & 3.22 & 0.561 \\
\hline
\end{tabular}

C1, Cyanex 272; C2, Cyanex 923; D, DOSO; T, TBP.

$D_{\mathrm{A}}$, distribution coefficient of $\mathrm{Zr}(\mathrm{IV})$ with extractant; $D_{\mathrm{B}}$, distribution coefficient of $\mathrm{Zr}(\mathrm{IV})$ with synergist; $D_{\mathrm{A}+\mathrm{B}}$, distribution coefficient of the mixture; $\Delta D, D_{\mathrm{A}+\mathrm{B}}-\left(D_{\mathrm{A}}+D_{\mathrm{B}}\right)$; S.C, $\log D_{(\mathrm{A}+\mathrm{B})} /\left(D_{\mathrm{A}}+D_{\mathrm{B}}\right)$.

mixed-solvent system was utilized to study the extraction behavior of zirconium using a mixture of extractants: Cyanex 272, Cyanex 923, DOSO and TBP.

Synergistic studies were carried out while keeping the concentration of one of the extractant constant at $0.005 \mathrm{M}$ and varying the other (synergist) over the range of 0.001 to $0.007 \mathrm{M}$. The $\mathrm{Zr}(\mathrm{IV})$ and $\mathrm{HCl}$ concentrations were kept at $0.001 \mathrm{M}$ and $0.01 \mathrm{M}$, respectively. The experimental data of the three synergistic systems, i.e. Cyanex 272, Cyanex 923, DOSO and TBP, are presented in Table 3. In all three systems, the synergistic coefficient (S.C) values varied marginally with an increase of the synergist concentration. The results show that TBP is the best synergist $(\mathrm{S} . \mathrm{C}=0.56)$ and DOSO is the least one (S.C $=0.18)$. Thus, the extractants can be arranged in the order of their synergism as TBP > Cyanex $923>$ DOSO.

\section{IR spectra of a zirconium complex}

The IR spectra of a zirconium complex with Cyanex 272 and pure extractant for a comparison were recorded. In the IR spectra of Cyanex 272, the bands in the region $2748-1700 \mathrm{~cm}^{-1}$ are due to aggregative $\mathrm{P}-\mathrm{OH}$ vibrations between intermolecular hydrogen bonding in the dimeric form. The band at $1170 \mathrm{~cm}^{-1}$ is due to $\mathrm{P}=\mathrm{O}$ stretching and the band at $1048 \mathrm{~cm}^{-1}$ is assigned to a $\mathrm{P}-\mathrm{O}-\mathrm{H}$ stretch. In the spectra of the $\mathrm{Zr}$-Cyanex 272 complex, bands due to aggregative $\mathrm{P}-\mathrm{OH}$ vibrations in the region 2748 $1700 \mathrm{~cm}^{-1}$ are absent. The band due to the $\mathrm{P}-\mathrm{O}-\mathrm{H}$ stretching is also absent. These results suggest that when the dimeric Cyanex 272 molecule forms a complex with zirconium(IV), the hydrogen atom of $\mathrm{P}-\mathrm{O}-\mathrm{H}$ is displaced by $\mathrm{Zr}$, thus confirming the proposed cation-exchange mechanism. Further, the shift in the $\mathrm{P}=\mathrm{O}$ stretching band from $1171 \mathrm{~cm}^{-1}$ to $1000 \mathrm{~cm}^{-1}$ is indicative of the participation of oxygen in $\mathrm{P}=\mathrm{O}$ group in complex formation through coordination.

A survey of literature revealed that Cyanex 272 has not been exploited for the extraction of zirconium. The present study on the liquid-liquid extraction of $\mathrm{Zr}(\mathrm{IV})$ from acidic chloride solutions by Cyanex 272 revealed the transfer of metal by a cation-exchange mechanism. The variation of the $D$ values with an increase of the extractant concentration showed a linear plot with a slope of $\sim 2$ and the IR spectra of the metal complex indicate that the extracted species was $\mathrm{ZrO}\left(\mathrm{HA}_{2}\right)_{2}$. An increase in the temperature had a positive influence on $\mathrm{Zr}(\mathrm{IV})$ extraction and stripping. Regeneration and recycling of the extractant indicated a greater stability of Cyanex 272 .

\section{Acknowledgements}

The authors express their sincere thanks to the Ministry of Environment \& Forests (MOEF), Government of India, New Delhi, India for the financial support. Thanks are also to Dr. B. M. Choudary, Head, Inorganic \& Physical Chemistry Division and Dr. K. V. Raghavan, Director, IICT, Hyderabad for their constant encouragement and permission to publish this work. Thanks are also due to Cytec Canada for providing Cyanex 272 free sample.

\section{References}

1. A. Levitt and E. Freund, J. Am. Chem. Soc., 1956, 78, 1545.

2. K. Alcock, F. C. Bedford, W. H. Hardwick, and H. A. C. Mokay, J. Inorg. Nucl. Chem., 1957, 4, 100.

3. S. Siekierski, J. Inorg. Nucl. Chem., 1959, 2, 129.

4. G. F. Egorov, V. V. Fomin, Yu. G. Frolov, and G. A. Yagodin, Zhur. Neog. Khim., 1960, 5, 1044.

5. S. S. Korovin, E. N. Lebedeva, A. M. Renzik, L. N. Komissarova, and G. P. Kuznetsova, Khim. I. Khim. Tekhnol., 1962, 5, 231.

6. A. M. Golub and V. N. Sergunkin, Zh. Prikil. Khim., 1970, 43, 1203.

7. H. Umezawa and R. Hara, Anal. Chim. Acta, 1961, 25, 360.

8. P. H. Tedesco, V. B. De Rumi, and J. A. Gonzalez Quintana, J. Inog. Nucl. Chem., 1967, 29, 1307.

9. S. S. Korovin, A. M. Renzik, E. N. Lebedova, and I. A. Apraksin, Org. Reagenty Anal. Khim. Tsirkoniya., 1970, 63.

10. G. A. Yagodin and V. V. Tarasov, Radiokhimiya, 1970, 12, 664.

11. R. K. Biswas and M. A. Hayat, Hydrometallurgy, 2002, 63(2), 149.

12. P. K. Mishra, V. Chakravortty, K. C. Dash, N. R. Das, and S. N. Bhattacharyya, J. Radioanal. Nucl. Chem., 1989, 134(2), 259.

13. D. L. Mcisaac and J. D. Baker, Solv. Extr. Ion Exch., 1983, 1(1), 27.

14. J. Sun, C. Wang, D. Li, and D. Ye, Fenxi. Huaxue, 1995, 23(9), 998.

15. K. N. Brewer, R. S. Herbst, T. A. Todd, and J. D. Christian, Solv. Extr. Ion Exch., 1998, 119(3), 1047.

16. W. A. Rickelton, D. S. Flett, and D. W. West, Solv. Extr. Ion Exch., 1984, 2, 815.

17. B. R. Reddy and P. V. R. Bhaskara Sarma, Miner. Metall. Process., 2001, 18(3), 172.

18. K. Sarangi, B. R. Reddy, and R. P. Das, Hydrometallurgy, 1999, 52(3), 253.

19. Y. Nagaosa and Y. Binghua, Talanta, 1997, 44, 327.

20. Z. Marczenko, "Spectrophotometric Determination of Elements", 1976, John Wiley \& Sons, 555, 609.

21. S. R. Mohanty and A. S. Reddy, J. Inorg. Nucl. Chem., 1975, 37, 1791.

22. R. K. Biswas and D. A. Begum, Hydrometallurgy, 1998, 49, 263.

23. K. C. Sole and J. B. Hiskey, Hydrometallurgy, 1995, 37, 129.

24. C. A. Blake, C. F. Baes, K. B. Brown, C. F. Coleman, and J. C. White, Proc. U. N. Intern. Conf. Peaceful uses At. Energy, 2nd ed., 1958, Vol. 28, Geneva, 289. 